\title{
Research and Development on the MPPT Intelligent Control Device for WPVC Power Generation System
}

\author{
${ }^{1}$ Zhongnian LI, ${ }^{2}$ Lei ZHOU \\ ${ }^{1}$ New energy Resuorce Engineering Department, Nantong Polytechnic College, Nantong, \\ 226002, China \\ ${ }^{2}$ School of Electronic Information and Electrical Engineering, Shanghai Jiao Tong \\ University,Shanghai, 200240,China
}

Keywords: intelligent, WPVC, D/D/D-D/D/AD, MPPT, PV

\begin{abstract}
A new type of WPVC(Wind Photo Voltaic Complementary) power generation system is researched \& developed, the system performance-cost ratio is high, the" $\mathrm{D} / \mathrm{D} / \mathrm{D}$ "(Directcurrent/Direct-current/Duty-ratio)-"D/D/ $\triangle \mathrm{D}$ "(Direct-current /Direct-current/ $\triangle$ Duty-ratio) MPPT (Maximum Power Point Tracking) intelligent control methods and facilities are used. The experimental results show that: "D/D/D-D/D/ $\triangle \mathrm{D}$ " intelligent regulation \& control method for MPPT, not only is simple, sensitive, accurate, convenient, utility and economy, now the intelligent system \& facilities have been running at the new energy application technology training base of Nantong Polytechnic College.
\end{abstract}

\section{Introduction}

In this paper, a new type of WPVC(Wind Photo Voltaic Complementary) power generation system is researched \& developed, the system can make full use of wind and solar energy resources to power generation. During the day, may have solar PV(Photo Voltaic) resources better, night may have good wind resources. Especially possess solar \& wind energy resource rich and good complementary region, the great economic benefit and social benefit. In order to overcome the uncertainty of wind \& solar energy to caused the power generation system imbalance, and further enhance the WPVC power generation system robustness, must create the intelligent control[1][2] facilities to the sake of achieve excellent automatic MPPT (Maximum Power Point Tracking), with WPVC generation power system optimal control, load optimal allocation and optimal WPVC system combination.

\section{MPPT control method for wind power generation facilities}

In wind energy power generation MPPT control mode is often: discrete MPPT control method, the wind speed automatic tracking MPPT control method, the wind turbine speed feedback MPPT control method etc, performance cost ratio is not high for the methods, in this paper a high performance-cost ratio "D/ D/ D " (Direct- current / Direct- current / Duty-ratio) MPPT control method is researched \& developed. I.e. by duty ratio adjustable PWM(Pulse Width Modulation) drive signal from the controller, can realization for adjustable the output voltage \& current of the system. At the same time detection voltage of wind energy generator and the controller set safety voltage value comparison: if more than the safety voltage then by power switch tube in the series to adjust the output power. When the accumulator full of or in the strong wind started unloading circuit for unloading to ensure safety. The D/D/D-MPPT control method, also is by the soft \& hardware of controller to regulate DC/DC duty ratio, thereupon to regulate the power output of the generator, so as to realize objectives of the MPPT. On the basis of the impedance matching On the basis of impedance matching get maximum power theory: "when a linear circuit load equivalent resistance with the internal resistance of power source are equal, load can be get the maximum power". visible MPPT is in essence the impedance transformation. Herefore, by the regulation \& control for $\mathrm{D} / \mathrm{D} / \mathrm{D}$ to keep the system always for impedance matching condition, and can realize MPPT. Wind power machine load power with $\mathrm{DC} / \mathrm{DC}$ duty ratio "D" characteristic 
curve shown figure 1, among them, each kind of wind speed is respectively corresponding to the maximum power point only.

\section{MPPT control method for power generation facilities on the solar PV}

Solar PV power generation output is not only related with the intensity of sunlight and temperature, but also related with the components working voltage of PV cells, only to make it work in the specific operating voltage, can be optimized to the maximum power point. MPPT Method \& facilities for PV power generation is researched of how to make PV components work under specific operating voltage. PV components I-V and P-V characteristics as shown figure 2, obviously the maximum power point with the environmental changes. By adjusting the PV battery component constant work point, so that it always work in the vicinity of the maximum power point, this is MPPT function.The MPPT control algorithm by adjusting the load impedance to regulate the output voltage, so the P-V curves for PV cell component as shown figure 2.

The MPPT method is widely used in PV power generation facilities, such as: constant voltage method, perturbation method, incremental conductance method, but performance cost radio of the methods is not high. How to find optimal method of high performance cost ratio, it is crucial. " $\mathrm{D} / \mathrm{D} / \triangle \mathrm{D}$ " method is researched \& developed in this paper, it is in this context to created, the basic pattern of this method is:

$$
D_{k}=D_{k-1}+\Delta D
$$

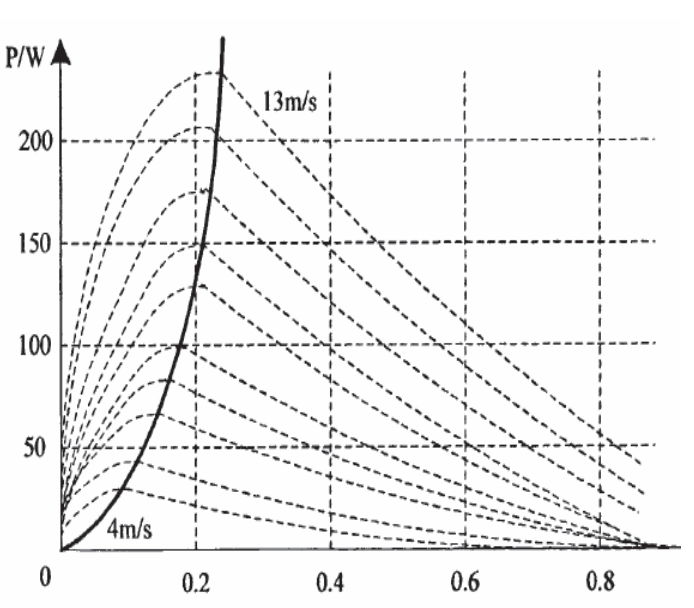

Fig.1: Wind power crew P-D characteristic curve

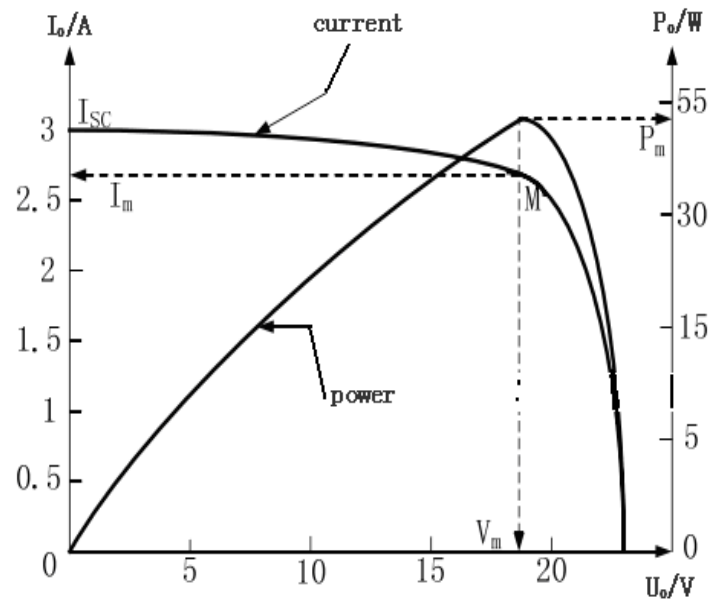

Fig.2: $\mathrm{I}-\mathrm{V}$ and $\mathrm{P}-\mathrm{V}$ curves for PV component

where $D_{K}$ and $D_{K-1}$ are Respectively $K$ and $k-1$ moment the duty ratio. If the $\triangle D$ fixed is step, $\triangle D$ selected too large, easy to cause concussion, and $\triangle D$ selected too small, the dynamic performance of MPPT become inferior. By this paper research shows that, if $\triangle D$ is a variable, this can solve well the problem for the above fixed step appears. Because even for the same a system, under different state, $\triangle D$ choice for dynamic \& steady state performance are very affected. But by the dynamic change " $\triangle D$ " value can make MPPT optimization fast realization. Because the output power of PV facilities for[3]:

$$
P=U_{P V} I_{P V}
$$

If using the $\mathrm{DC} / \mathrm{DC}$ circuit facilities, then the load voltage:

$$
U_{O}=U_{P V} D
$$

The output power of PV cell component:

$$
P_{P V}=U^{2}{ }_{P V} D^{2} /\left(\eta \mathrm{R}_{l}\right)
$$


Practical applications $\eta$ can be regarded as constant, when $R_{l}$ unchanged, then may be thought:

$$
P_{P V} \propto K * \mathrm{U}_{P V} D
$$

In the formula $K$ is constant coefficient, this paper set $K$ is 1 , convenient for the formula is derivated. When the power reaches the maximum, first order derivative of $\mathrm{P}$ to $\mathrm{D}$ :

$$
\left(d P_{P V}\right) /(d D)=U_{P V}(d / d D) D+D(d / d D) U_{P V}
$$

So the criterion can be approximated as $\mathrm{M}=\mathrm{U}_{\mathrm{PV}} \triangle \mathrm{D}+\mathrm{D} \triangle \mathrm{U}_{\mathrm{PV}}$, when $\mathrm{M}>0, \mathrm{U}_{\mathrm{PV}}<\mathrm{U}_{\max }, \mathrm{D}_{\mathrm{K}}=\mathrm{D}_{\mathrm{K}}$ ${ }_{1}+\triangle \mathrm{D}$, when $\mathrm{M}<0, \mathrm{U}_{\mathrm{PV}}>\operatorname{Umax}, \mathrm{D}_{\mathrm{K}}=\mathrm{D}_{\mathrm{K}-1}-\triangle \mathrm{D}$, when $\mathrm{M}=0, \mathrm{U}_{\mathrm{PV}}=\mathrm{U}_{\max }, \mathrm{D}_{\mathrm{K}}=\mathrm{D}_{\mathrm{K}-1}$, in the above all formulas choose of the $\triangle \mathrm{D}$, influence for performance of the system is very important. In order to make the system has strong adaptability, in this paper, using the initialization time by calculation model for parameters setting automatically. "D"update rules is: [5]

$$
D_{K}=D_{K-1}+K_{D} M
$$

Where $K_{D}$ at initialization time using calculation model setting automatically by initial state , i.e.[6]

$$
K_{D}=/ \triangle D_{0} / M_{0} /
$$

This only detection output voltage of PV cells components, according to system operation state, it can dynamically changing step iteration, this makes the sensitivity of MPPT further improve. Because the step size by calculation model to set automatically according system state, so very convenient. [7]

\section{D/D/D-D/D/ $\Delta$ D Facility}

In this paper research on the MPPT control method (i.e.D/D/D-D/D/ $\triangle \mathrm{D}$ ) for wind \& PV power generation system, involved the basic framework of the WPVC controller as shown figure 3, mainly consist of : wind power crew, solar (PV) cell array, intelligent controller, inverter, battery etc parts. The intelligent controller includes DSP control nuclear, switch,"D/D/D-D/D/ $\triangle \mathrm{D}$ regulator", LCD liquid crystal display device, driving circuit, sampling and detection circuit (i.e.wind generator voltage detection, the PV array voltage detection, the battery voltage detection, rectifier output current \& inverter input current detection, battery charge and discharge current detection \& temperature detection device) devices etc. [8]

\section{Conclusion}

In carry on wind power generation system MPPT, wind power \& PV can share one D/D, and which can greatly reduce the cost of the system but also simplify the control strategy, and by DSP implementation software control, generate the corresponding PWM drive signal on grid of each power switch tube, to regulate the duty ratio of switch tube to achieve MPPT intelligent control. By DSP controlled D/D in each switching cycle "reduce voltage/rise voltage" not arise in one switching period at the same a moment, i.e. at reduce voltage, rise voltage stop, and at rise voltage, reduce voltage stop. Then go round and begin again the work.

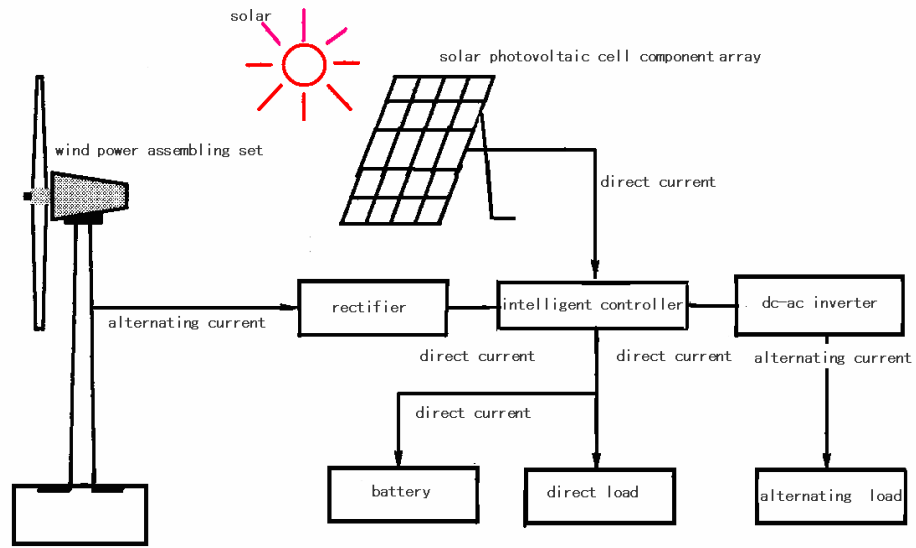

Fig.3: Basic structure of the WPVC controller 
The wind power generation facilities / the PV cell assembly facilities / WPVC facilities have been running on the WPVC experimental platform, and by the data acquisition module to detect respectively the output power for the three kinds of facilities as shown table 1. Can be seen from table 1, when the PV output

Table 1: Output power for the WPVC power generation system

\begin{tabular}{lllllllll}
\hline hour & $5 \mathrm{~h}$ & $6 \mathrm{~h}$ & $7 \mathrm{~h}$ & $8 \mathrm{~h}$ & $9 \mathrm{~h}$ & $10 \mathrm{~h}$ & $11 \mathrm{~h}$ & $12 \mathrm{~h}$ \\
Wind- $\mathrm{P}_{\mathrm{O}}$ & 80 & 86 & 94 & 81 & 37 & 61 & 52 & 57 \\
PV-P $_{\mathrm{O}}$ & 16 & 38 & 37 & 45 & 31 & 56 & 49 & 52 \\
WPVC-P $_{\mathrm{O}}$ & 95 & 123 & 130 & 137 & 70 & 115 & 100 & 110 \\
\hline hour & $13 \mathrm{~h}$ & $14 \mathrm{~h}$ & $15 \mathrm{~h}$ & $16 \mathrm{~h}$ & $17 \mathrm{~h}$ & $18 \mathrm{~h}$ & $19 \mathrm{~h}$ & $20 \mathrm{~h}$ \\
Wind- $\mathrm{P}_{\mathrm{O}}$ & 57 & 43 & 40 & 88 & 78 & 79 & 80 & 77 \\
PV-P $_{\mathrm{O}}$ & 47 & 49 & 48 & 46 & 45 & 19 & 16 & 04 \\
WPVC-P $_{\mathrm{O}}$ & 101 & 90 & 88 & 131 & 121 & 96 & 94 & 83 \\
\hline
\end{tabular}

power and wind power output power is influenced by the outside world changes, The MPPT of WPVC power generation system based on the $\mathrm{D} / \mathrm{D} / \mathrm{D}-\mathrm{D} / \mathrm{D} / \triangle \mathrm{D}$ control method, which can quickly and accurately tracking the external environment change, making the system output power remained at the maximum output power value or so, i.e. the power generation system has good robustness. But also do not appear the system output power at the maximum power point near occurred the phenomenon of "power oscillation". This paper relates to the experiments were completed in New Energy Engineering Department of Nantong Polytechnic College(our work unit) experimental training base for new energy application technology and the experimental platform for WPVC power generation system, the core device of controller for the WPVC power generation system \& experimental platform for the WPVC power generation system see respectively Figure 4 and Figure 5.

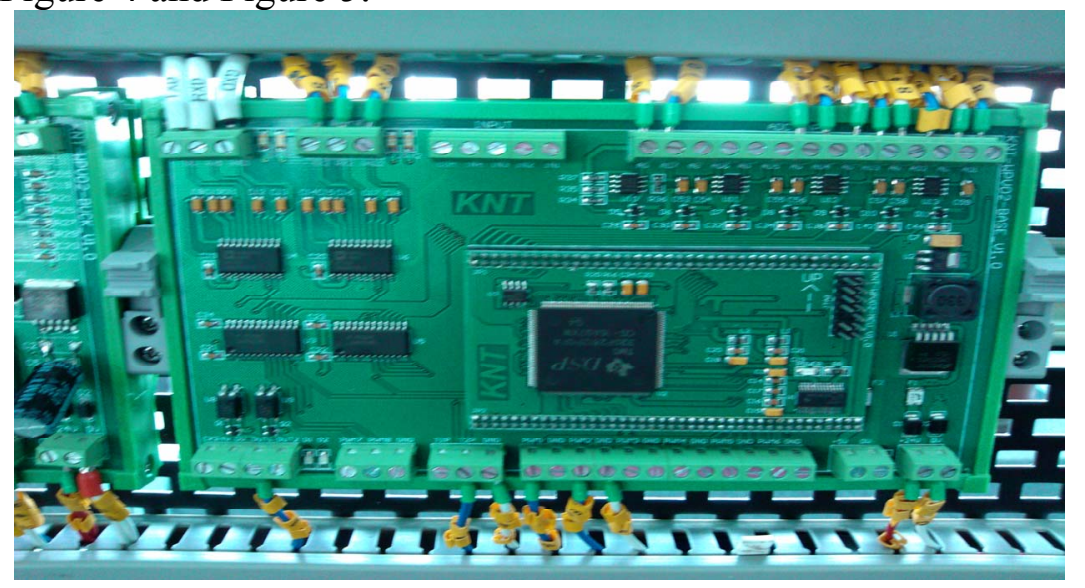

Fig.4: Core device of controller for the WPVC power generation system

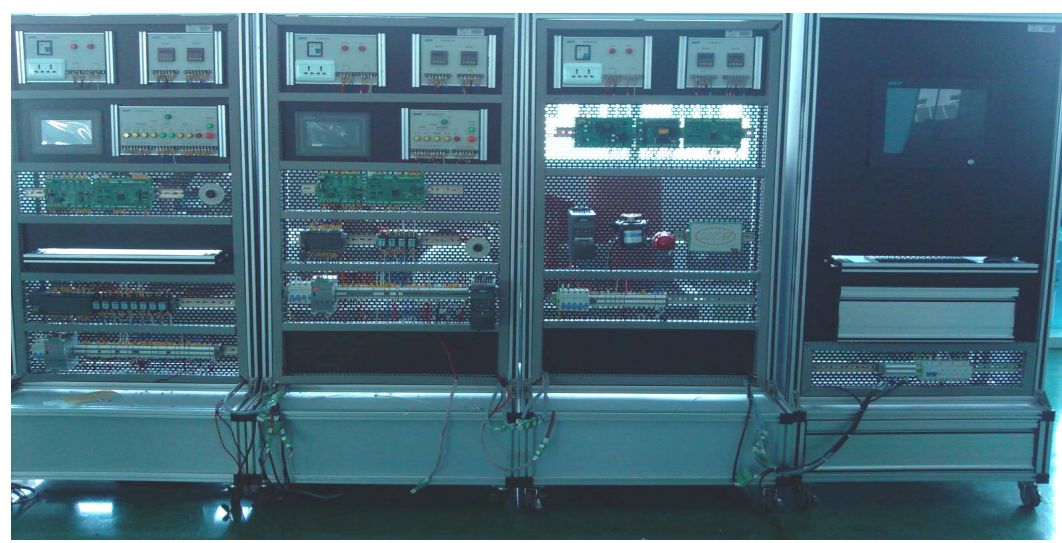

Fig.5: Experimental platform for the WPVC power generation system 


\section{References}

[1] Li Zhong-Nian \& Zhou-Lei, Research on conditioning and Application for the $F^{2} N^{2}$.Advanced Materials Research, pp.1089-1092, October, 2014.

[2] Li Zhong-Nian \& Zhou-Lei, Research on the fault diagnosis system for ICM. Advanced Materials Research, pp.894-897, March,2013.

[3] Li Zhong-Nian, Construction and Operation on the Training Base for Application Technology about New Energy Resuorce. Advanced Materials Research, pp.986-989,June, 2012.

[4] Li Zhong-Nian \& Zhou-Lei, Research on Fault Diagnosis Method for ECS-CNCL Based on Rough Set. Proc. of IEEE ICNC-FSKD '12, pp.1023-1026, May,2012.

[5] Li Zhong-Nian, Zhou Xin \& Chen Yong-Hong, Research for the Intelligent RMB Sorter Based on ANN. Proc. of ICEMI'2009, IEEE, Beijing, China, pp99-102, August, 2009.

[6] Li Zhong-Nian \& Huang-Tao, Research on Theory Method and Key Technology for Electric Corona Purifying Tail Gas of Automobile. Applied Mechanics and Materials, pp.1264-1267, March, 2013.

[7] Li Zhong-Shi, Desig \& Construction \& Application for Solar PV Generating Power System. Beijing:People Post and Telecommunications Press, October, 2012.

[8] Li Zhong-Nian, Electronic Control Technology \& PLC. Beijing: Tsinghua University Press, Twelve, 2014. 